\title{
The impact of comprehension of disease-related information and perceptions regarding effects and controllability on protective and social solidarity behaviors with regard to COVID-19
}

\author{
Aysun Danayiyen $^{1}$ (D) Zeynep Kavsur $^{2}$ (D) $\cdot$ Semra Baysan $^{3}$ (D) \\ Received: 31 May 2020 / Accepted: 5 October 2020 / Published online: 15 October 2020 \\ (C) Springer-Verlag GmbH Germany, part of Springer Nature 2020
}

\begin{abstract}
Aim The main theme in health behavior theories is that risk perception goes hand in hand with knowledge of the disease, perceived effects, and perceived controllability of the disease. This study aims to investigate the impact of all those variables on protective and social solidarity behaviors concerning COVID-19.

Subject and methods This cross-sectional study was conducted in the early stages of the outbreak in Turkey. Data were collected between April 1 and April 6, 2020, via an online survey. The reliability of the scales was tested. Exploratory factor analysis was used to examine construct validity. SEM analysis was employed to determine the model.

Results SEM analysis indicates that fit indices $(\chi 2=4.108 \mathrm{df}=2 ; \chi 2 / \mathrm{df}=2.05$; RMSEA $=0.04 ; \mathrm{CFI}=0.99 ; \mathrm{GFI}=0.99$; PCLOSE $=0.545$ ) were good model fits. The structural analysis indicated that the comprehensibility of information, perceived effects and controllability of the disease, and social solidarity had a statistically significant direct positive effect on protective behavior ( $\beta=0.133, p<0.001 ; \beta=0.399, p<0.001 ; \beta=0.084, p<0.001 ; \beta=0.171, p<0.001$, respectively).

Conclusion A health behavior model in the literature was evaluated with the data for a society facing a pandemic risk, and it was shown that the data fit the model perfectly. The study has revealed that understanding the information about COVID-19 increases social solidarity. Most importantly, it is concluded that social solidarity increases society's protective behaviors. Participants did not find COVID-19-related information to be comprehensible. Despite disease uncertainty in the early stage of the pandemic, participants had a high perception of the severity of COVID-19.
\end{abstract}

Keywords Health behavior Perceived severity $\cdot$ Perceived control $\cdot$ Protective behavior $\cdot$ COVID-19 knowledge $\cdot$ Social solidarity

Aysun Danayiyen

aysun.danayiyen@okan.edu.tr

Zeynep Kavsur

zeynep.kavsur@marmara.edu.tr

Semra Baysan

sbaysan@ciu.edu.tr

1 Faculty of Health Sciences, Okan University, Tuzla, İstanbul, Turkey

2 Faculty of Health Sciences, Marmara University, Maltepe, İstanbul, Turkey

3 Institute of Graduate Studies and Research, Cyprus International University, Nicosia, Cyprus

\section{Introduction}

Pneumonia cases with "unknown causes" were first reported in Wuhan, China, on December 31, 2019 (WHO 2020a). The cause was later found to be a new coronavirus, and the disease was named coronavirus disease-19 (COVID-19). The spread of infection from the novel coronavirus $(2019-\mathrm{nCoV})$ that emerged from China was declared a "pandemic" on March 11, 2020, after the disease had spread to 113 countries (WHO 2020b). Turkey reported its first case on the same day (Sağlık Bakanlığı 2020). On January 10, 2020, the Ministry of Health in Turkey established a scientific advisory committee to combat COVID-19. Two months later, the Turkish public became aware of the committee's work as its recommendations to suspend schools and implement protective measures such as hand hygiene and self-isolation were announced. The focus of this committee's actions during the new pandemic 
has been to diagnose the pathophysiology of the agent causing the disease and to provide treatment protocols. It was unclear at the time how the public would perceive and respond to the many complex issues related to COVID-19. According to Leung et al., policies for protective health behaviors should be based on a full understanding of the perceptions of risk and anxiety levels of the public (Leung et al. 2003).

In addition to the identification of new organisms, the development of vaccines, and the introduction of appropriate treatments, ensuring public awareness of the risks and precautions is one the most important measures taken to control outbreaks (Vartti et al. 2009). If the threat or risk is not fully perceived, it sets the stage for an acceleration of the outbreak, as we observed during the bird flu and SARS outbreaks (Tan and Enderwick 2006; Odabaşı and Ertong 2011). Describing the concept of the world risk society, Beck (2006) argues that there is a tendency in modern society to disregard risks or not to take them seriously. Previous experiences with large outbreaks of serious diseases reveal that a lack of risk perception can easily cause community inertia and insufficient adoption of measures (Leung et al. 2003). According to theories of health behavior, in particular, voluntary involvement in protective measures depends on modern society's perceptions of risks regarding health threats (Kwok et al. 2020).

The main theme in common health behavior theories, including the health belief model and the protection motivation theory, is that risk perception goes hand in hand with knowledge of the disease, perceived effects, and perceived controllability of the disease (Tabak 1999; Çınarlı 2008; Kwok et al. 2020). According to those models, three important factors affect people's self-protection behavior. The first of these is the perception that they will be impacted by the disease, the second is the level of knowledge regarding the disease, and the third is the perception that the disease can be controlled (Tabak 1999; Çınarlı 2008). First, the literature states that perceived impact is motivation for compliance with protective behaviors (Bish and Michie 2010). Perception of the impact of the disease is expected to lead to positive outcomes as a result of taking precautions (Payaprom et al. 2011). For example, Brug et al. (2004) found that Dutch people were aware of the outbreak and knew about SARS but did not act to protect themselves because there had been no cases. Perceived impact is the strongest predictor of changes in health behavior as reported in the literature on health promotion. Second, knowledge about the health threat is necessary for there to be changes in health behavior. It is reported that even a minimum level of knowledge can play an active role in health behavior changes (Payaprom et al. 2010). Finally, individuals will not act in a protective manner unless they perceive that the disease can be overcome or prevented, or that the severity of the disease can be reduced by taking protective measures (Tabak 1999). The perception of disease controllability means that individuals understand that they can control the outcome by taking precautions, preventing disease, receiving treatment, etc., and this perception will motivate the individual to healthier behavior. The health behavior of the community in the early stages of fighting a pandemic, when there is no cure or vaccine, is important. The effectiveness of the measures depends on the degree to which society voluntarily complies with protective health behaviors such as wearing masks, practicing hand hygiene, and practicing self-isolation (Kwok et al. 2020). It is hypothesized in this study that protective action increases depending on knowledge about the disease, perceptions of the impact of the disease, and perceptions of its controllability.

Another important issue in the COVID-19 pandemic is the social solidarity shown by the community against this threat. If diseases are passed from person to person and become a pandemic, social relations can be altered. It is expected that social distance must be maintained in order to prevent its spread, and that cooperation and solidarity (even at the global level) will be effective in combating the pandemic. The concept of social solidarity includes social interest and cooperation, which are of great importance in Adlerian thought (Adler 1927) and highlighted by Maslow (1954) as a step of selfactualization. In Adlerian thought, the person who is educated within the society wants to make the world a better place with his/her actions (Eker 2012). Altruism, the behavior of assisting or helping someone without any expectations, emerges in this way (Kasser and Ryan 1993). It has been demonstrated that behaviors that define individualism in pandemics can increase the likelihood of pathogen transmission and reduce compliance with measures, while collectivism can increase compliance with protective behaviors (Fincher et al. 2008). In order to make the world a better place in terms of struggle, the individual can take action to participate in social solidarity during the pandemic. In this study, it is expected that knowledge of COVID-19, perceived effects, and perceived controllability will increase social solidarity. Social solidarity may positively affect compliance with protective behavior.

Conducted in the early stages of the COVID-19 pandemic, this study aims to investigate the impact of society's comprehension of disease-related information, the perception of disease impact, and the perception of controllability of the disease on protective behavior and social solidarity.

\section{Methods}

This cross-sectional study was conducted online in accordance with the ethical standards for the research specified in the ethical principles of the American Psychological Association (American Psychological Association 2017). The ethics committee approval for this cross-sectional study was obtained from Okan University in Istanbul. Data were collected between April 1, 2020, and April 6, 2020, with an 
online questionnaire. A data set of 700 participants was evaluated after the disqualification of incomplete questionnaires and questionnaires submitted by anyone under the age of 16 .

On the basis of the literature review, questions that measure the comprehensibility of information about COVID-19, perceptions regarding the effects and controllability of the disease, and preventive health behavior were used with the permission of the national questionnaire conducted in the People's Republic of China (Li et al. 2020). Regarding the translation of the test, Brislin (1970) and White and Elander (1992) propose one or more of the following techniques: forward and back translation, two bilingual translators, committee approach, and pre-test (Maneeesriwongul and Dixon 2004). The committee approach was adopted in this study. A committee consisting of three people independently translated the questions into Turkish and then met to assess their comprehensibility and suitability.

The questionnaire consisted of four parts. The first part contained questions about the demographics of the participants. The second part consisted of questions measuring comprehension of COVID-19 information, perceptions of the impact of COVID-19, and perceptions of the controllability of COVID-19. Participants' self-reported levels of comprehension were measured with 11 questions and subjects covering the etiology of COVID-19, methods of transmission and treatment, symptoms, diagnostic criteria, etc. Participants described their level of comprehension by scoring each item on a five-point Likert scale. High scores indicate that participants had higher comprehension of information about COVID-19. The perceived impact of COVID-19 was measured with five items, where participants assessed the adverse effects of the infection rate on morbidity, mortality, the social order, and the economy. The participants scored their perceptions regarding the impact of the disease on a five-point Likert scale. The perception of the controllability of the disease was measured through nine items, for example, "How controllable is the infectiousness of COVID-19?" The participants indicated the extent to which various aspects of the disease (e.g. the means of transmission and treatment, symptoms of COVID19, and diagnostic criteria) could be controlled by grading each item on a five-point Likert scale. High scores indicate that it can be controlled completely.

In the third part, protective health behaviors of the participants were measured with 10 items. Participants were asked to specify their frequency of displaying protective behaviors such as wearing and constantly changing face masks and washing hands for protection against COVID-19, using a five-point Likert scale. A higher score indicates that the participants exhibited more protective behaviors.

The last part contained five statements to measure the level of social solidarity, such as "I help those in need in my community" and "I donate time and work as a volunteer and donate money or materials to non-governmental organizations or related institutions." Questions measuring social solidarity during the pandemic were taken from the study by Li et al. (2020) based on the study by Kasser and Ryan (1993).

Total item correlations and Cronbach's alpha coefficients were calculated to test the reliability of the scales. The construct validity was tested through exploratory factor analysis and confirmatory factor analysis. The relationships between the variables were examined with a Pearson correlation test. Structural equation modeling and path analysis were used for impact assessment. IBM SPSS 24 and IBM SPSS AMOS 24 software programs were used to analyze the data.

\section{Results}

\section{Descriptive statistics}

A total of 700 individuals participated in the study, $66.7 \%$ (467) of whom were female. The educational backgrounds of the participants were as follows: $62.1 \%$ (435) university graduates, $22.1 \%$ (155) high school graduates, $11.1 \%$ (78) college graduates, and $4.6 \%$ (32) secondary school and elementary school graduates. When participants were asked to assess their own health status, $81.2 \%$ (568) said they were fine or quite fine; $81.2 \%$ (569) of the participants did not have any physical health problems, while $95.1 \%$ (666) did not have any mental health problems. The average age of the participants in the study was 34.03 years, and the standard deviation (SD) was \pm 14.89 . Table 1 shows the descriptive findings among the participants.

\section{Validation of variables}

Questions that constitute the variables to be measured were translated into Turkish. A committee approach was adopted to identify and correct inconsistencies in the translation process and to make it possible to assess comprehensibility and appropriateness. A committee of three people independently translated the test into Turkish and then assessed its comprehensibility and suitability. After the Turkish translation of the scales was tested for suitability, the scales were subjected to a construct validity test and the Cronbach's alpha values were examined to measure reliability.

Exploratory factor analyses were conducted using principal components analysis and the promax rotation technique. Sample competencies of the analyses were tested according to the Kaiser-Meyer-Olkin (KMO) value and Bartlett's test of sphericity.

Table 2 shows the mean variance explanations and Cronbach's alpha coefficients obtained from the factor analysis of each scale.

From the analyses conducted on 11 statements measuring comprehension of information about COVID-19 in all 
Table 1 Summary of demographic variables

\begin{tabular}{|c|c|c|c|c|c|c|c|}
\hline \multirow[t]{3}{*}{ Gender } & & $n$ & $\%$ & Self-reported chronic physical diseases & & $n$ & $\%$ \\
\hline & Female & 467 & 66.7 & & No & 569 & 81.3 \\
\hline & Male & 233 & 33.3 & & Yes & 131 & 18.7 \\
\hline \multirow[t]{5}{*}{ Education } & Elementary school & 11 & 1.6 & Self-reported current health status & Extremely poor & 4 & 0.6 \\
\hline & Secondary school & 21 & 3.0 & & Poor & 25 & 3.6 \\
\hline & High school & 155 & 22.1 & & Average & 103 & 14.7 \\
\hline & College & 78 & 11.1 & & Good & 300 & 42.9 \\
\hline & University & 435 & 62.1 & & Very good & 268 & 38.3 \\
\hline \multirow[t]{2}{*}{ Age } & Mean & $\mathrm{SD}$ & & Self-reported psychiatric disorder & No & 666 & 95.1 \\
\hline & 34.038 & 14.89 & & & Yes & 34 & 4.9 \\
\hline
\end{tabular}

aspects, a KMO value of 0.857 was determined, and the result of Bartlett's test of sphericity was found to be significant $(p<0.001)$. The sample size was sufficient. The ratio of total variance explained by the statements in one dimension was $41.98 \%$. The factor loadings of the items were between 0.727 and 0.538 . The Cronbach's alpha value of the variable was 0.857 . The scale was reliable and valid. Knowledge about COVID-19 levels was slightly above average, with a mean value of 3.6. On matters such as the symptoms of COVID19 disease, its contagiousness, contagion rate, treatment criteria, recovery, and mortality rates, participant responses ranged between "neither comprehensible nor incomprehensible" and "comprehensible."

From the analysis of the five items measuring the perceived severity of COVID-19, a KMO value of 0.803 was determined, and Bartlett's test of sphericity was found to be significant $(p<0.001)$. The sample size was sufficient. The ratio of total variance explained by the statements in one dimension was $63.74 \%$. The factor loadings of the items were between 0.866 and 0.649 . The Cronbach's alpha value of the statements was 0.837 . The scale was valid and reliable. The mean value regarding the perception of the severity of COVID-19 was 4.4. The participants' perception of the impact of the disease was remarkably high.

In the analysis of the nine items measuring the perception of controllability of COVID-19, the KMO value was 0.878 and Bartlett's test of sphericity was found to be significant $(p<0.001)$. The sample size was sufficient. The ratio of total variance explained by the statements in one dimension was $55.51 \%$. The factor loadings for the statements were between 0.841 and 0.612, and Cronbach's alpha for the COVID-19 controllability perception was 0.896 . The scale was reliable and valid. The mean perception of controllability of the disease among the participants was 3.19. Participants perceived the disease to be somewhat controllable.

For the 10 statements measuring protective behaviors, the KMO value was 0.863 and Bartlett's test of sphericity was found to be significant $(p<0.001)$. The sample size was sufficient. The variance of the statements explained in one dimension was $50.36 \%$. The Cronbach's alpha value of the scale was 0.853 . The scale was found to be reliable and to have construct validity. The factor loadings of the statements collected under one dimension varied between 0.869 and 0.486 . The mean value of the protective behaviors of the participants regarding the COVID-19 disease pandemic was 4.19. This indicates that they often performed protective behaviors.

In the analysis of the social solidarity scale, the KMO value was 0.684 and Bartlett's test of sphericity was significant $(p<0.001)$. The sample size was sufficient. The variance of social solidarity was $51.64 \%$, and the statements were collected in one dimension. The factor loadings of the items were between 0.797 and 0.619 . The Cronbach's alpha value of

Table 2 Descriptive statistics of variables

\begin{tabular}{|c|c|c|c|c|c|c|c|c|c|}
\hline Variables & $\begin{array}{l}\text { Number of } \\
\text { items }\end{array}$ & $\begin{array}{l}\text { Possible } \\
\text { range }\end{array}$ & M & $\mathrm{SD}$ & $\alpha$ & KMO & $\begin{array}{l}\text { Bartlett's test of } \\
\text { sphericity }\end{array}$ & $\begin{array}{l}\text { Factor loading range of } \\
\text { the items }\end{array}$ & $\begin{array}{l}\text { Explanatory } \\
(\%)\end{array}$ \\
\hline 1 Social solidarity & 5 & $1-5$ & 3.4 & 0.69 & 0.760 & 0.684 & $p<0.001$ & $0.797-0.619$ & 51 \\
\hline $\begin{array}{l}2 \text { Comprehension of COVID-19 } \\
\text { information }\end{array}$ & 11 & $1-5$ & 3.6 & 0.65 & 0.858 & 0.857 & $p<0.001$ & $0.727-0.538$ & 41 \\
\hline 3 Perceived severity & 5 & $1-5$ & 4.4 & 0.60 & 0.837 & 0.803 & $p<0.001$ & $0.866-0.649$ & 63 \\
\hline 4 Perceived controllability & 9 & $1-5$ & 3.1 & 0.72 & 0.896 & 0.878 & $p<0.001$ & $0.841-0.612$ & 55 \\
\hline 5 Protective behavior & 10 & $1-5$ & 4.1 & 0.69 & 0.853 & 0.863 & $p<0.001$ & $0.869-0.486$ & 50 \\
\hline
\end{tabular}


social solidarity was 0.760 . The scale was reliable and valid. The mean value of social solidarity was 3.43 . The participants' efforts towards social solidarity in the early stages of the COVID-19 pandemic were moderate.

\section{Bivariate correlation of variables}

The correlations between the variables used in the study were analyzed by Pearson's correlation test before using structural equation modeling.

Table 3 shows the correlations between the variables.

The results of the analysis showed a significant positive correlation between social solidarity and the comprehensibility of the information $(r=0.229 ; p<0.001)$. There was a significant but small positive correlation between comprehension of COVID-19 information and protective behavior $(r=0.211$; $p<0.001)$.

Although there was a significant positive correlation $(r=$ $0.370 ; p<0.001)$ between the participants' perceptions of the impact of COVID-19 and protective behavior, there was no correlation between the perception of impact and social solidarity.

Finally, there was a significant positive correlation between the perception of controllability of COVID-19 and social solidarity $(r=0.148 ; p<0.001)$. There was also a significant positive correlation between controllability and protective behavior $(r=0.194 ; p<0.001)$.

\section{Structural equation model (SEM) and path analysis}

Before constructing the structural equation model (SEM) used in this research, the relationships between all variables were taken into consideration. Alternative models were tested with the relevant items of all the included scales, and the model showing the best fit was identified.

According to the analyzed fitness values $(\chi 2=4108 \mathrm{df}=2$; $\chi 2 / \mathrm{df}=2.05 ; \mathrm{RMSEA}=0.04 ; \mathrm{CFI}=0.99 ; \mathrm{GFI}=0.99$; PCLOSE $=0.545$ ), the model fitted the data perfectly. Figure 1 shows the protective behavior model based on the literature review and the direct impacts of the comprehension of COVID-19 information and perceptions of impact and controllability on this model. Furthermore, the impacts of the comprehension of COVID-19 information and the perception of impact on social solidarity are shown. Figure 1 shows standardized direct impact values of the variables.

This is important, as it shows the power of the variables to predict the regression values, i.e. the factor loadings. The regression values of the variables and the indirect and direct standardized impact values are collectively shown in Table 4.

Table 4 shows that the knowledge of COVID-19, perception of severity and controllability of COVID-19, and social solidarity together account for $20 \%\left(\mathrm{R}^{2}=0.203\right)$ of the total variance in protective behaviors. The direct effect of knowledge of COVID-19 on protective behaviors is 0.133 . That is, due to the unmediated effect of it on protective behaviors when knowledge of COVID-19 increases by 1, protective behaviors increase by 0.133 . As hypothesized, understanding COVID-19 was related to increased protective behaviors.

The direct effect of the controllability of COVID-19 on protective behaviors is 0.084 . When controllability of COVID-19 increases by 1 , protective behavior increases by 0.084 . As hypothesized, controllability had a direct effect on protective behaviors, but this was not strong in the study.

The direct effect of the perceived severity on protective behaviors is 0.399 . Protective behaviors increase by 0.399 when the perceived severity increases by 1 . This is in addition to any mediated effect that the perceived severity may have on protective behaviors. As hypothesized, perception of severity had stronger direct effects on protective behaviors than did any of the variables in the study. Moreover, both its direct and total effects were significantly stronger than those of the other variables.

One of the most striking results is that the direct effect of social solidarity on protective behavior is 0.171 . That is, due to the unmediated effect of social solidarity on protective behavior, when social solidarity increases by 1 , protective behavior increases by 0.171 . This is in addition to any mediated effect that social solidarity may have on protective behavior. The impact of perceived COVID-19 severity on social solidarity is not significant. It is stated above that the $p$ value is below 0.05 for the correlation between perceived severity and social solidarity. However, the direct (unmediated) effect of
Table 3 Bivariate correlation of variables

\begin{tabular}{|c|c|c|c|c|c|c|c|c|c|}
\hline & & 1 & & 2 & & 3 & & 4 & \\
\hline 1 & Social solidarity & & & & & & & & \\
\hline 2 & $\begin{array}{l}\text { Comprehension of COVID-19 } \\
\text { information }\end{array}$ & 0.229 & $* * *$ & & & & & & \\
\hline 3 & Perceived severity of COVID-19 & 0.042 & & 0.045 & & & & & \\
\hline 4 & Perceived controllability of COVID-19 & 0.148 & $* * *$ & 0.393 & $* * *$ & 0.096 & $* *$ & & \\
\hline 5 & Protective health behavior & 0.225 & $* * *$ & 0.211 & $* * *$ & 0.371 & $* * *$ & 0.194 & $* * *$ \\
\hline
\end{tabular}


Fig. 1 Model of the precautionary behavior

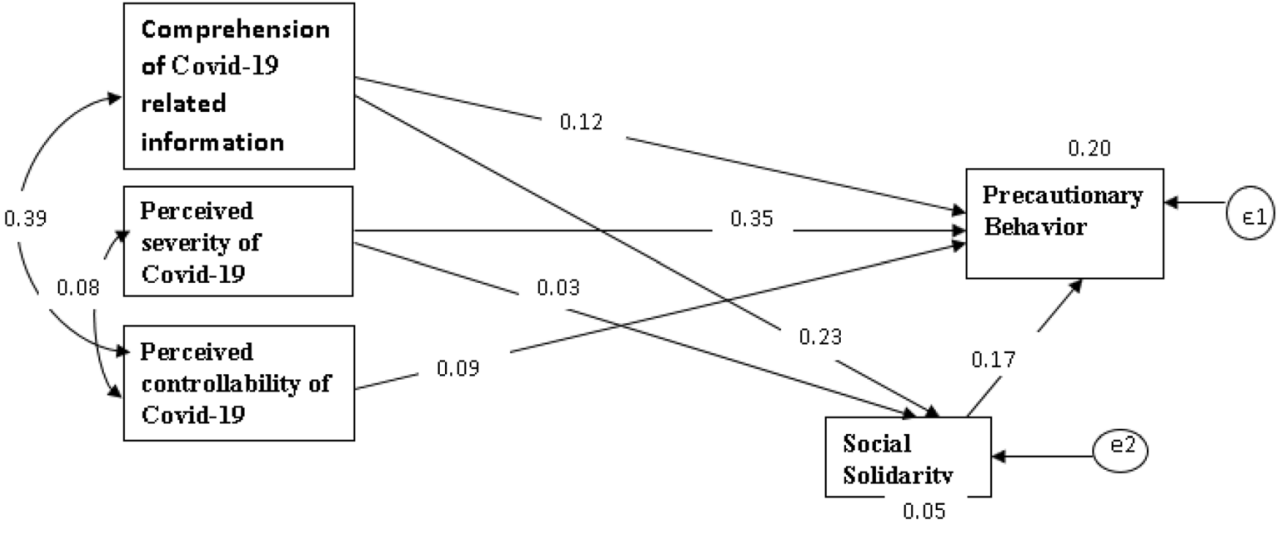

knowledge of COVID-19 on social solidarity is 0.242 , and the direct effect of perception of severity on social solidarity is 0.032. As hypothesized, except for perception of the severity of COVID-19, all variables had a direct effect on social solidarity, and social solidarity had a direct effect on protective behavior. On the other hand, no significant mediated effect of any variables on protective behavior was detected.

\section{Discussion}

This study has several theoretical and practical results. First, this study specifically focused on changes in the health behaviors of participants during an accelerated pandemic. Based on health behavior theories, a research model was created that examines the effects of knowledge of COVID-19, the perceived impact and controllability of COVID-19, and the social solidarity in increasing the level of protective behavior against the COVID-19 pandemic. A health behavior model in the literature was evaluated with the data for a society facing a pandemic risk, and it was shown that the data fit the model perfectly. Accordingly, knowledge of COVID-19, the perceived impact and controllability of the disease, and social solidarity collectively increased protective behaviors by $20 \%$.

Information about the symptoms, contagiousness, contagion rate, treatment criteria, recovery, and mortality rates of COVID-19 was not completely "comprehensible" by participants. This may be because of the lack of available information, as the disease is new and there is little information about it. It is reported that even a minimum level of knowledge about a disease can play an active role in effecting a change in health behavior (Payaprom et al. 2011). It was also found in this study that protective behaviors will increase when information about COVID-19 is better understood. International experiences mostly from the literature related to HIV/AIDS show that the most effective factor in health behavior change is an emphasis on continuity of information (Leung et al. 2003). In this respect, it may be suggested to increase compliance with the measures and to increase efforts towards health education and promotion in terms of their overall effectiveness.

Despite the uncertainty in the early stages of COVID-19 (including contagiousness, mode of transmission, and pathogenicity), individuals in the community have a high perception of the impact of disease. The perception of its impact, which is the average of the effects of COVID-19 on infection, morbidity/mortality rates, social order, and economy, is high. Turkish society often acts cautiously, and this is mostly affected by the perceived impact of a disease. It has been reported in the literature that a minimum threat or risk perception is effective in compelling people to take the expected action to change their health behavior. For instance, it was reported that face masks were worn by $75.8 \%$ of the population during the peak of the SARS pandemic in Hong Kong (Leung et al.

Table 4 Regression coefficient of variables of the model

\begin{tabular}{|c|c|c|c|c|c|}
\hline \multicolumn{2}{|l|}{ Dependent variables } & \multirow{2}{*}{$\begin{array}{l}\text { Variables } \\
\text { Comprehension of information }\end{array}$} & \multirow{2}{*}{$\begin{array}{l}\text { Estimate } \\
0.242 * * *\end{array}$} & \multirow{2}{*}{$\begin{array}{l}\text { Standardized direct effects } \\
0.227^{* * *}\end{array}$} & \multirow{2}{*}{$\begin{array}{l}\text { Standardized indirect effects } \\
0.000\end{array}$} \\
\hline Social solidarity & $\leftarrow$ & & & & \\
\hline Social solidarity & $\leftarrow$ & Perceived impact & 0.036 & 0.032 & 0.000 \\
\hline Protective behavior & $\leftarrow$ & Comprehension of information & $0.133 * * *$ & $0.124 * * *$ & 0.039 \\
\hline Protective behavior & $\leftarrow$ & Perceived controllability & $0.084 * * *$ & $0.087 * * *$ & 0.000 \\
\hline Protective behavior & $\leftarrow$ & Perceived impact & $0.399 * * *$ & $0.350 * * *$ & 0.005 \\
\hline Protective behavior & $\leftarrow$ & Social solidarity & $0.171 * * *$ & $0.170 * * *$ & 0.000 \\
\hline
\end{tabular}

$N=700 ; * * p<0.05$; *** $p<0.001$; protective behavior $\mathrm{R}^{2}=0.203$; social solidarity $R^{2}=0.05$ 
2003). Thus, since 2003, it has not been uncommon in Hong Kong for individuals with acute respiratory diseases to wear surgical masks to protect those around them (Lau et al. 2005). In this study, $50.4 \%$ of participants stated that they wore masks. Moreover, there was no mandate on mask wearing in the early stages of the disease when this study was being conducted. The Ministry of Health of the Republic of Turkey made it compulsory to wear masks in public on April 10, 2020. Among the participants, $78.1 \%$ said they washed their hands very often, while $70.4 \%$ said they used disinfectants or cologne (a traditional alcohol-based hand cleanser). A total of $52.1 \%$ of the participants were trying to eat a balanced diet. It was observed that all precautions were followed at a high level. However, it has been observed in previous pandemics that high perceptions of impact can lead to anxiety disorders, and extreme anxiety can cause panic (Leung et al. 2003). It is suggested that future studies investigate this issue.

The perception of controllability of COVID-19 has a positive impact on protective behaviors among participants. A person's perception of being able to control the disease indicates his or her attitude towards overcoming the disease, preventing it, or reducing its severity by taking precautions. In other words, if individuals think that they cannot control the disease no matter what they do, they will not take action, because they believe that they cannot escape the threat (Tabak 1999). In this respect, the results of the study are consistent with the literature. Increased perception of controllability leads to increased protective behavior. It was found that the sense of uncontrollability associated with the disease increased anxiety and led to extreme threat assessment in cases of H1N1 flu (Taha et al. 2014). The participants in this study think that COVID-19 is somewhat controllable. Therefore, the benefits of compliance with the measures should be shared with the public. It should be frequently emphasized in the messages of the Health Ministry that pandemic control is in the hands of the individual and depends on the measures to be taken.

As debates about the reshaping of social relations in the world due to the pandemic continue, this study focused on the concept of social solidarity. Participants sometimes exhibited actions such as informing others to prevent the spread of COVID-19, helping those in need, and making donations in the early stages of the COVID-19 disease. The study has revealed that understanding the information about COVID-19 increases social solidarity. Most importantly, it is concluded that social solidarity increases society's protective behaviors. In a similar study, Fincher et al. (2008) found that collectivism can increase compliance with protective behavior in situations where pathogens are common. In this respect, further research is needed on the effect of social solidarity in increasing protective behaviors.
The study has several limitations. Many of the participants (467) were female and were university graduates (435), as the data was collected through an online survey method, and it is common to have mostly female participants and those with a high level of education in online survey studies ( $\mathrm{Li}$ et al. 2020; Geldsetzer 2020a). The online survey started on the 20th day of the COVID-19 pandemic in Turkey, and the survey was open for 1 week. The stability of the answers against time is not known. However, rapid online surveys are a promising method for assessing and tracking knowledge and perceptions during rapidly evolving infectious disease outbreaks (Geldsetzer 2020b). Furthermore, it is recommended that changes in health behaviors in a pandemic should be monitored and the attitudes of the public should be compared with other times. Additionally, changes in health behavior over time may allow policymakers to solve general problems, especially if such a survey is made at different stages of the pandemic.

Acknowledgements The authors would like to express their special gratitude to Kirstin Ozturk for the editing of this manuscript.

Author contributions All authors contributed to the study conception and design. Material preparation, data collection, and analysis were performed by Aysun Danayiyen, Zeynep Kavsur, and Semra Baysan. The first draft of the manuscript was written by Aysun Danayiyen, and all authors commented on previous versions of the manuscript. All authors read and approved the final manuscript.

\section{Compliance with ethical standards}

Informed consent Informed consent was obtained from all individual participants included in the study.

Ethical approval All procedures performed in studies involving human participants were in accordance with the ethical standards of the Istanbul Okan University research committee (Ref. No. 56665618-204.01.07) and the 1964 Helsinki declaration and its later amendments or comparable ethical standards.

Conflict of interest The authors declare that they have no conflict of interest.

\section{References}

Adler A (1927) Individual psychology. J Abnorm Soc Psychol. https:// doi.org/10.1037/h0072190

American Psychological Association (2017) American psychological association. ethical principles of psychologists and code of conduct. Am Psychol. https://doi.org/10.1037/0003-066X.57.12.1060

T.C. Sağlık Bakanlığı (2020) T.C. Sağlık Bakanlığı Halk Sağlığı Genel Müdürlüğü COVID-19 (SARS-CoV-2 ENFEKSIYONU) rehberi. Ankara

Beck U (2006) Living in the world risk society. Econ Soc. https://doi.org/ $10.1080 / 03085140600844902$ 
Bish A, Michie S (2010) Demographic and attitudinal determinants of protective behaviours during a pandemic: a review. Br J Health Psychol. https://doi.org/10.1348/135910710X485826

Brislin RW (1970) Back-translation for cross-cultural research. J CrossCult Psychol. https://doi.org/10.1177/135910457000100301

Brug J, Aro AR, Oenema A et al (2004) SARS risk perception, knowledge, precautions, and information sources, the Netherlands. Emerg Infect Dis 10:1486. https://doi.org/10.3201/eid1008.040283

Çınarlı İ (2008) Sağlık İletişimi ve Medya. Nobel Yayın Dağıtım, Ankara

Eker S (2012) Alfred Adler'in kișilik kuramı'nın demokrasi düșüncesi açisindan önemi. UÜ Fen-Edebiyat Fakültesi Sos Bilimler Dergisi 13:157-180

Fincher CL, Thornhill R, Murray DR, Schaller M (2008) Pathogen prevalence predicts human cross-cultural variability in individualism/ collectivism. Proc R Soc B Biol Sci 275:1279-1285. https://doi. org/10.1098/rspb.2008.0094

Geldsetzer P (2020a) Knowledge and perceptions of COVID-19 among the general public in the United States and the United Kingdom: a cross-sectional online survey. Ann Intern Med. https://doi.org/10. $7326 / \mathrm{m} 20-0912$

Geldsetzer P (2020b) Use of rapid online surveys to assess people's perceptions during infectious disease outbreaks: a cross-sectional survey on COVID-19. J Med Internet Res 22:e18790. https://doi. org $/ 10.2196 / 18790$

Kasser T, Ryan RM (1993) A dark side of the American dream: correlates of financial success as a central life aspiration. J Pers Soc Psychol 65:410-422. https://doi.org/10.1037//0022-3514.65.2.410

Kwok KO, Li KK, Chan $\mathrm{HH}$ et al (2020) Community responses during the early phase of the COVID-19 epidemic in Hong Kong: risk perception, information exposure and preventive measures. medRxiv. https://doi.org/10.1101/2020.02.26.20028217

Lau JTF, Yang X, Tsui HY, Kim JH (2005) Impacts of SARS on healthseeking behaviors in general population in Hong Kong. Prev Med (Baltim). https://doi.org/10.1016/j.ypmed.2004.11.023

Leung GM, Lam TH, Ho LM et al (2003) The impact of community psychological responses on outbreak control for severe acute respiratory syndrome in Hong Kong. J Epidemiol Community Health

Li J, Yang A, Dou K, et al (2020) Chinese public's knowledge, perceived severity, and perceived controllability of the COVID19 and their associations with emotional and behavioural reactions, social participation, and precautionary behaviour: A national survey. PsyArXiv 1-30. https://doi.org/10.31234/osf.io/5tmsh

Maneeesriwongul W, Dixon JK (2004) Instrument translation process: a methods review. J Adv Nurs 48:175-186. https://doi.org/10.1001/ archotol.1987.01860040098030

Maslow A (1954) Self-actualizing people. In: Motivation and personality, New York, pp 149-180

Odabaşı ZY, Ertong G (2011) Social effects of avian influenza: a comparison of Turkey and Indonesia. Sosyoloji Araştırmaları Dergisi 14 (1)

Payaprom Y, Bennett P, Burnard P et al (2010) Understandings of influenza and influenza vaccination among high-risk urban dwelling Thai adults: a qualitative study. J Public Health (Bangkok). https:// doi.org/10.1093/pubmed/fdp086

Payaprom Y, Bennett P, Alabaster E, Tantipong H (2011) Using the health action process approach and implementation intentions to increase flu vaccine uptake in high risk Thai individuals: a controlled before-after trial. Health Psychol. https://doi.org/10.1037/ a0023580

Tabak RS (1999) Sağlık İletişimi. Literatür Yayıncılık, İstanbul

Taha SA, Matheson K, Anisman H (2014) H1N1 was not all that scary: uncertainty and stressor appraisals predict anxiety related to a coming viral threat. Stress Heal. https://doi.org/10.1002/smi.2505

Tan WJ, Enderwick P (2006) Managing threats in the global era: the impact and response to SARS. Thunderbird Int Bus Rev. https:// doi.org/10.1002/tie.20107

Vartti AM, Oenema A, Schreck M et al (2009) SARS knowledge, perceptions, and behaviors: a comparison between Finns and the Dutch during the SARS outbreak in 2003. Int J Behav Med 16:41-48. https://doi.org/10.1007/s12529-008-9004-6

White M, Elander G (1992) Translation of an instrument. Scand J Caring Sci. https://doi.org/10.1111/j.1471-6712.1992.tb00145.x

World Health Organization (2020a) Novel Coronavirus ( 2019-nCoV ) Situation Report - 121 January 2020. WHO Bull 1-7

World Health Organization (2020b) Coronavirus disease 2019 (COVID19) situation report - 51. 11 March 2020

Publisher's note Springer Nature remains neutral with regard to jurisdictional claims in published maps and institutional affiliations. 